\title{
Article \\ Effect of Multistage High Temperature Thermomechanical Treatment on the Microstructure and Mechanical Properties of Austenitic Reactor Steel
}

\author{
Sergey Akkuzin ${ }^{1, *}$, Igor Litovchenko ${ }^{1,2} \mathbb{D}$, Nadezhda Polekhina ${ }^{1}$, Kseniya Almaeva ${ }^{1}$, Anna Kim ${ }^{2}$, \\ Evgeny Moskvichev ${ }^{1,2}$ (D) and Vyacheslav Chernov ${ }^{3}$
}

1 Institute of Strength Physics and Materials Science of the Siberian Branch of the Russian Academy of Sciences (ISPMS SB RAS), 2/4, Akademicheskii pr., 634055 Tomsk, Russia; litovchenko@spti.tsu.ru (I.L.); nadejda89tsk@yandex.ru (N.P.); kseni_ya_almaeva@mail.ru (K.A.); em_tsu@mail.ru (E.M.)

2 Faculty of Physics, National Research Tomsk State University, 36, Lenina pr., 634050 Tomsk, Russia; aneeta.2001@list.ru

3 A.A. Bochvar High-Technology Research Institute of Inorganic Materials (JSC «VNIINM»), 5a, Rogova St., 123098 Moscow, Russia; VMChernov@bochvar.ru

* Correspondence: akkuzin.spti@mail.ru; Tel.: +7-952-162-41-43

check for

updates

Citation: Akkuzin, S.; Litovchenko, I.; Polekhina, N.; Almaeva, K.; Kim, A.; Moskvichev, E.; Chernov, V. Effect of Multistage High Temperature Thermomechanical Treatment on the Microstructure and Mechanical Properties of Austenitic Reactor Steel. Metals 2022, 12, 63. https://doi.org/ $10.3390 /$ met12010063

Academic Editor: Sunghyuk Park

Received: 1 December 2021

Accepted: 27 December 2021

Published: 28 December 2021

Publisher's Note: MDPI stays neutral with regard to jurisdictional claims in published maps and institutional affiliations.

Copyright: (C) 2021 by the authors. Licensee MDPI, Basel, Switzerland. This article is an open access article distributed under the terms and conditions of the Creative Commons Attribution (CC BY) license (https:// creativecommons.org/licenses/by/ $4.0 /)$.

\begin{abstract}
The deformation microstructures formed by novel multistage high-temperature thermomechanical treatment (HTMT) and their effect on the mechanical properties of austenitic reactor steel are investigated. It is shown that HTMT with plastic deformation at the temperature decreasing in each stage $\left(1100,900\right.$, and $600{ }^{\circ} \mathrm{C}$ with a total strain degree of $\left.e=2\right)$ is an effective method for refining the grain structure and increasing the strength of the reactor steel. The structural features of grains, grain boundaries and defective substructure of the steel are studied in two sections (in planes perpendicular to the transverse direction and perpendicular to the normal direction) by Scanning Electron Microscopy with Electron Back-Scatter Diffraction (SEM EBSD) and Transmission Electron Microscopy (TEM). After the multistage HTMT, a fragmented structure is formed with grains elongated along the rolling direction and flattened in the rolling plane. The average grain size decreases from $19.3 \mu \mathrm{m}$ (for the state after solution treatment) to $1.8 \mu \mathrm{m}$. A high density of low-angle boundaries (up to $\approx 80 \%$ ) is found inside deformed grains. An additional cold deformation ( $e=0.3$ ) after the multistage HTMT promotes mechanical twinning within fragmented grains and subgrains. The resulting structural states provide high strength properties of steel: the yield strength increases up to $910 \mathrm{MPa}\left(\right.$ at $20^{\circ} \mathrm{C}$ ) and up to $580 \mathrm{MPa}$ (at $650{ }^{\circ} \mathrm{C}$ ), which is 4.6 and 6.1 times higher than that in the state after solution treatment (ST), respectively. The formation of deformed substructure and the influence of dynamic strain aging at an elevated tensile temperature on the mechanical properties of the steel are discussed. Based on the results obtained, the multistage HTMT used in this study can be applied for increasing the strength of austenitic steels.
\end{abstract}

Keywords: austenitic reactor steel; high temperature thermomechanical treatment; electron microscopy; deformation microstructures; grain refinement; twinning; mechanical properties; serrated flow

\section{Introduction}

Austenitic stainless steels are used as structural materials in various industries, including the nuclear power engineering [1-3]. In Russia, austenitic stainless steels ChS-68 (Fe-16Cr-15Ni-2Mo-Mn-Ti-V-B) and EK-164 (Fe-16Cr-19Ni-2Mo-2Mn-Nb-Ti-B) are used for the manufacture of fuel cladding shells of fast-neutron (Generation III) nuclear reactors BN-600 and BN-800 [4-6]. These steels have a number of attractive qualities, such as high ductility, increased heat resistance, lack of tendency to low-temperature embrittlement compared to other structural materials. A common problem limiting the use of austenitic steels in the nuclear power industry is their radiation-stimulated swelling at high irradiation doses. The studies of radiation porosity under irradiation in the BN-600 reactor 
(maximum damaging dose $77 \mathrm{dpa}$ ) $[5,6]$ showed that under identical irradiation conditions, steel EK-164 swells 1.5-2 times less than steel ChS-68. Some authors [5] attribute this to the increased content of $\mathrm{Ni}(19 \% \mathrm{wt}$.) and the complex system of alloying-the presence of $\mathrm{Ti}, \mathrm{Nb}, \mathrm{V}, \mathrm{B}, \mathrm{Si}$, etc. It was shown [5] that austenitic steel EK-164 is a radiation-resistant material ensuring fuel burn-up of over $15 \%$. At higher irradiation doses (more than $100 \mathrm{dpa}$ ) and higher fuel burnout, EK-164 and ChS-68 steels swell significantly, which limits their applications in nuclear power engineering.

Radiation swelling is affected by several factors [7]: solid-solution, dislocation and phase stability. The solid-solution influence is determined by the concentration of the alloying elements (primarily $\mathrm{Ni}$ ) and $\mathrm{C}, \mathrm{V}, \mathrm{Ti}, \mathrm{Nb}, \mathrm{Si}, \mathrm{B}$ in the solid solution. The second factor is determined by the substructure formed as a result of plastic deformation. The increased density of dislocation sinks for point defects inhibits the formation of pores under irradiation conditions. The phase stability of austenite determines the formation of precipitates, their compositions, volume fractions, location and morphology. These factors are interrelated with each other and determine the processes of pore nucleation and growth [7]. Optimization of these factors makes it possible to study the use of austenitic steels at higher (over $100 \mathrm{dpa}$ ) damaging irradiation doses.

Currently, cold rolling deformation (up to $20-30 \%$ ) is applied to form the substructure in austenitic steels used as shells of fuel elements [5]. This substructure is characterized by deformation twins and increased dislocation density (relative to solid solution treatment). These features of the microstructure of austenitic reactor steels determine the required long-term high-temperature strength properties and radiation resistance. An increase in the degree of cold deformation contributes to a more intensive deformation twinning with the formation of a high density of microtwin packets, which significantly reduces the ductility of steels [8,9]. The possibilities of thermomechanical treatments using hot and warm deformation to form the substructure and increase the mechanical properties in austenitic reactor steels have been little studied.

Previously, the possibility of improving mechanical properties and modifying the microstructure under conditions of HTMTs was shown on such austenitic steels as AISI $304[10,11], 310$ [12], 316 [13] and 321 [11,14,15]. Most of these works, focus on the formation of dynamic recrystallization (DRX) grains; the main methods for their formation are HTMT with hot rolling $[13,16]$ or compression $[12,17,18]$ with degrees of deformation $e=0.7-3$ in the temperature range of $800-1200{ }^{\circ} \mathrm{C}$. These treatments promote an intensive formation of DRX grains at high temperatures of $900-1200{ }^{\circ} \mathrm{C}$. In this case, a higher deformation temperature more strongly promotes the growth of DRX grains and an increase in the volume fraction of DRX [17]. Consequently, a similar structure formed by HTMT at high temperatures strengthens the steels but only slightly.

For example, in [13] the effect of warm plastic deformation in the temperature range of 500-900 ${ }^{\circ} \mathrm{C}$ with a total strain degree of $e=2$ on the microstructure and mechanical properties of austenitic steel AISI 316 is investigated. It was shown that these thermomechanical treatments lead to the development of grain fragmentation, an increase in the dislocation density, and the formation of DRX grains. It was noted that the lower was the plastic deformation temperature, the more fragmented and elongated grains were formed in the rolling direction. In addition, at low temperatures (below $600{ }^{\circ} \mathrm{C}$ ), the DRX processes are suppressed [13]. As a result, higher values of mechanical properties were achieved at a deformation temperature of $500{ }^{\circ} \mathrm{C}$ : yield strength of $945 \mathrm{MPa}$, elongation to failure of $10.5 \%$.

In [15], the effect of hot deformation at $1100{ }^{\circ} \mathrm{C}(e=1.6)$, and a sequence of hot deformation at $1100{ }^{\circ} \mathrm{C}(e=0.8)$ and warm deformation at $600{ }^{\circ} \mathrm{C}(e=0.7)$ on the microstructure and mechanical properties of 321 type austenitic steel is demonstrated. It is shown that HTMT, with decreasing temperature in the sequence of treatments, causes a high-intensity fragmentation of the steel structure and has a positive effect on the strength properties (yield strength of $677 \mathrm{MPa}$ ) while maintaining acceptable plasticity (elongation to fracture $12 \%$ ). 
The effect of HTMTs (including multistage HTMTs) on the microstructure features and mechanical properties of reactor-grade steels (type EK-164) has not been studied before.

In this paper, the effect of high-temperature thermomechanical treatment consisting of a sequence of plastic deformations with a decrease of temperature (hot, warm deformationmultistage HTMT) on the microstructure and mechanical properties of austenitic reactor steel EK-164 is studied.

\section{Materials and Methods}

The material used in this study was a Russian grade austenitic reactor steel EK-164, the chemical composition of which is presented in Table 1. Prior to deformation, the samples were solution treated (ST) at $1100{ }^{\circ} \mathrm{C}$ for $1 \mathrm{~h}$ followed by water quenching (Figure 1 ). Heating was carried out in a tubular electric furnace of the T-40/600 type (Plant "LETO", Tula, Russia). The temperature was determined by the furnace thermocouple. The rolling mill was maintained at room temperature. The initial samples size was $\approx 54 \times 11 \times 11 \mathrm{~mm}^{3}$.

Table 1. Chemical composition of the austenitic reactor steel EK-164 (wt. \%).

\begin{tabular}{cccccccccc}
\hline Fe & Ni & Cr & Mo & Mn & Si & Ti & Nb & V \\
\hline bal. & 17.92 & 15.93 & 2.4 & 1.74 & 0.68 & 0.4 & 0.28 & 0.12 & 0.07 \\
\hline
\end{tabular}

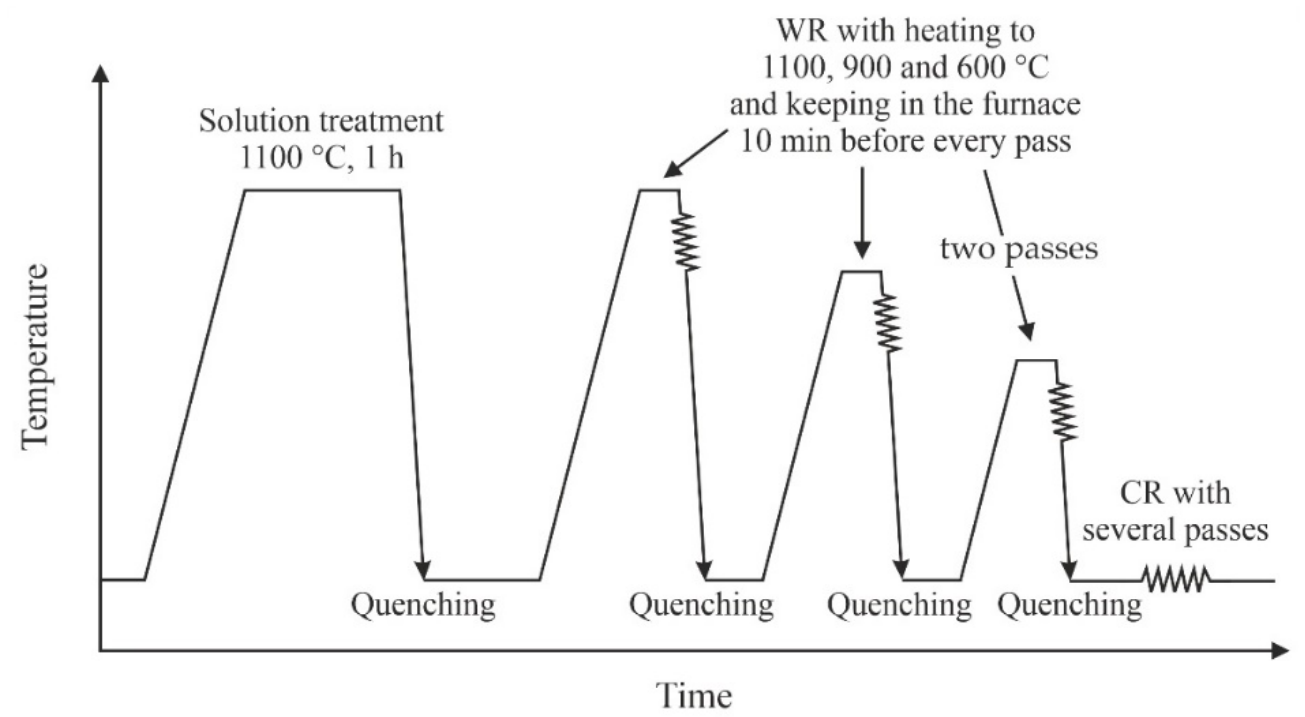

Figure 1. Scheme of multistage thermomechanical treatment.

HTMT consisted of a sequence of hot (HR) and warm (WR) plastic deformations by rolling. The first stage of processing consisted of plastic deformation to a strain degree of $e=0.7$ in 1 pass with preheating to $1100{ }^{\circ} \mathrm{C}$ (HTMT-1). The thickness of the samples after HTMT-1 decreased down to $\approx 5.5 \mathrm{~mm}$. The second stage of processing included HTMT-1 and subsequent plastic deformation to a strain degree of $e=0.7$ in 1 pass with preheating to $900{ }^{\circ} \mathrm{C}$ (HTMT-2). The thickness of the samples after HTMT-2 was $\approx 2.7 \mathrm{~mm}$. The third stage of treatment included HTMT-2 and subsequent rolling deformation in 2 passes with a total strain degree of $e=0.6$ (the thickness of the samples $\approx 1.6 \mathrm{~mm}$ ) with preheating to $600{ }^{\circ} \mathrm{C}$ (HTMT-3). The exposure of the samples in the furnace to these specified temperatures was $10 \mathrm{~min}$. The time between the removal of the samples from the furnace and the start of plastic deformation was about 3-5 s. After removal from the mill the samples were immediately quenched in water. After HTMT-3, cold deformation (CR) was performed at $20^{\circ} \mathrm{C}$ in 5 passes with a total strain degree of $e=0.3$ (HTMT-3 $+\mathrm{CR}$ ). The final thickness of the samples after thermomechanical treatments was $\approx 1.15 \mathrm{~mm}$.

The microstructural characterization was performed using a Tescan MIRA 3 LMU Field Emission scanning electron microscope (FE SEM) equipped with a Field Emission Gun 
(TESCAN ORSAY HOLDING, Brno, Czech Republic) and an Oxford Instruments Nordlys F electron backscatter diffraction detector (Oxford Instruments, High Wycombe, UK). The SEM EBSD samples were prepared by standard metallographic techniques: sandpaper grinding to \#2000, diamond polishing 9 to $1 \mu \mathrm{m}, 50 \mathrm{~nm}$ col-K suspension fine polishing. The final stage was ion milling for $25 \mathrm{~min}$ at $10 \mathrm{kV}$. Ion polishing was performed using a Technoorg Linda SEMPrep 2 system (Technoorg Linda Co. Ltd, Budapest, Hungary). The EBSD images were taken from the longitudinal (perpendicular to transverse direction-TD) and parallel to the rolling plane (perpendicular to normal direction-ND) sections. Further, these sections are designated as perpendicular to TD and ND, respectively. The EBSD data for ST samples were obtained with step sizes of 200 and $125 \mathrm{~nm}$ for the areas of 250 and $50 \mu \mathrm{m}^{2}$, respectively. After HTMT-3 the step size for these areas was 200 and $50 \mathrm{~nm}$, respectively. The microstructure was examined by the Oxford Instruments AZtec software (version 3.1, Oxford Instruments, High Wycombe, UK).

TEM and scanning TEM (STEM) investigations were conducted using the Philips CM-12 (FEI Company, Hillsboro, OR, USA) and JEOL JEM-2100 electron microscopes (JEOL Ltd., Akishimam Tokio, Japan) at an accelerating voltage of $120 \mathrm{kV}$ and $200 \mathrm{kV}$, respectively. Thin foils were prepared from the sections perpendicular to TD by electropolishing in an electrolyte containing $450 \mathrm{~mL}$ of orthophosphoric acid and $50 \mathrm{~g}$ of chromic anhydride.

Mechanical tests were carried out at room temperature $\left(20^{\circ} \mathrm{C}\right)$ and at high temperature close to the maximum nuclear reactor operating temperature $\left(650{ }^{\circ} \mathrm{C}\right)$ by the method of static tensile deformation at a strain rate of $\approx 2 \times 10^{-3} \mathrm{~s}^{-1}$ on a NIKIMT 1246R-2/2300 hightemperature vacuum testing machine (Experimental Plant "NIKIMP" (Research and Design Institute of Testing Machines, Instruments and Measuring Instruments), Moscow, Russia) using dog-bone samples with the gage length of $13 \mathrm{~mm}$ and gage section of $2 \times 1 \mathrm{~mm}^{2}$. Samples were cut from section parallel to the rolling plane. Tension was performed in the rolling direction. High temperature tensile tests were carried out in a vacuum of $\approx 2.5-3.5 \times 10^{-5} \mathrm{~Pa}$.

\section{Results}

\subsection{SEM EBSD and TEM Studies of Deformed Microstructure}

The results of the structure investigation of EK-164 steel in the ST state are presented in Figure 2. The phase map (Figure $2 \mathrm{a}$ ) shows that the microstructure consists of austenite with the average grain size of $\approx 19.3 \mu \mathrm{m}$. An analysis of the grain boundaries shown in Figure $2 \mathrm{a}$ and the distribution of grain misorientations shown in Figure $2 c$ suggests that the samples contain a high fraction of special type boundaries. The histogram of the grain distribution by the misorientation angles shows a pronounced peak near $60^{\circ}$ (Figure 2c). This peak corresponds to the annealing twins. The fraction of the special type $\Sigma 3$ boundaries (twin boundaries) is $68.2 \%$. At the same time, the fraction of high-angle boundaries is $97 \%$ and that of low-angle boundaries-3\%. Taking into account the annealing twins, the average grain size is $\approx 7.7 \mu \mathrm{m}$ (Figure $2 \mathrm{~d}$ ).

It should be noted that annealing twins are found in the grains with the width of several microns (Figure 2a,b) and those narrower than $1 \mu \mathrm{m}$ (Figure 2e,f). In addition, coarse (up to several $\mu \mathrm{m}$ ) particles of the MX type (where $\mathrm{M}-\mathrm{Nb}$, Ti or $\mathrm{V} ; \mathrm{X}-\mathrm{C}$ ) (Figure 2e,f) were found inside austenite grains. The volume fraction of these particles does not exceed $1 \%$. Earlier [19], it was shown by TEM that fine (from several $\mathrm{nm}$ to $50 \mathrm{~nm}$ ) MX particles based on vanadium were also observed in the structure of steel EK-164. These particles are not identified by EBSD methods due to their small size. 


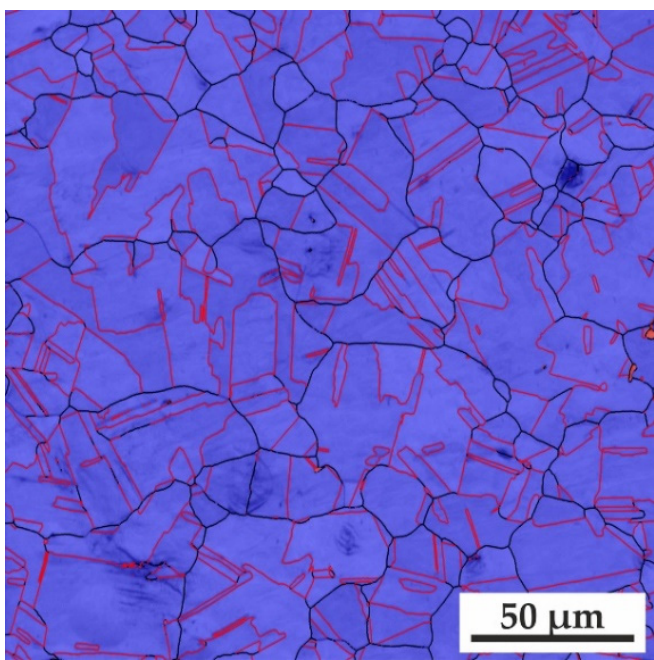

(a)

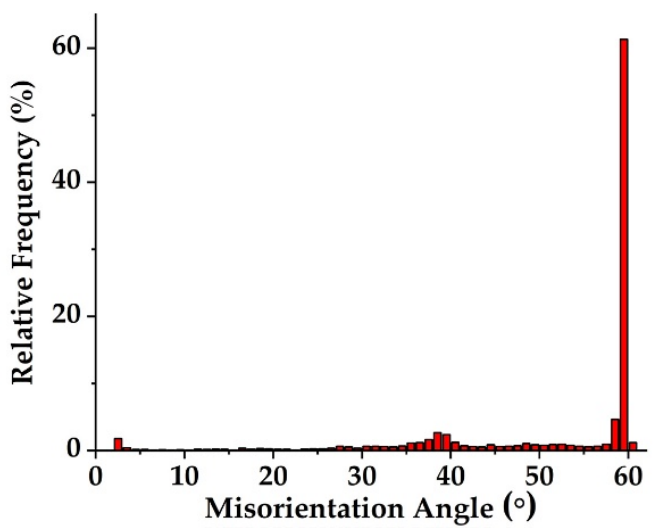

(c)

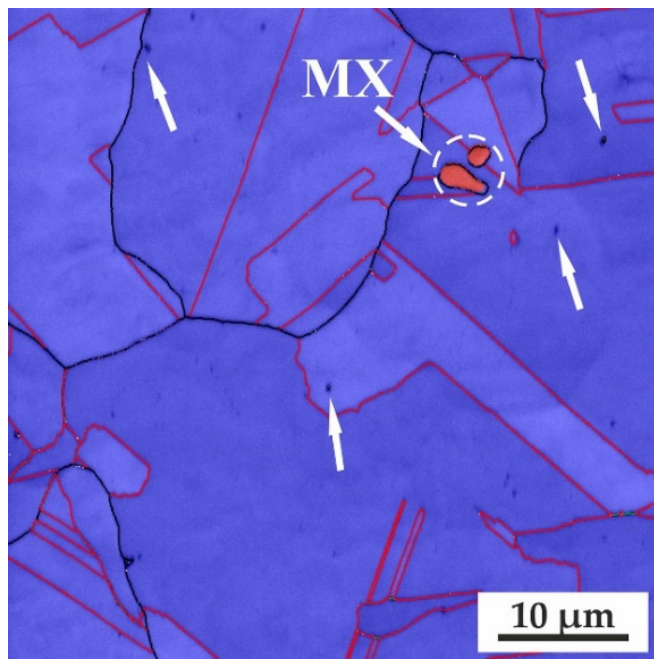

(e)

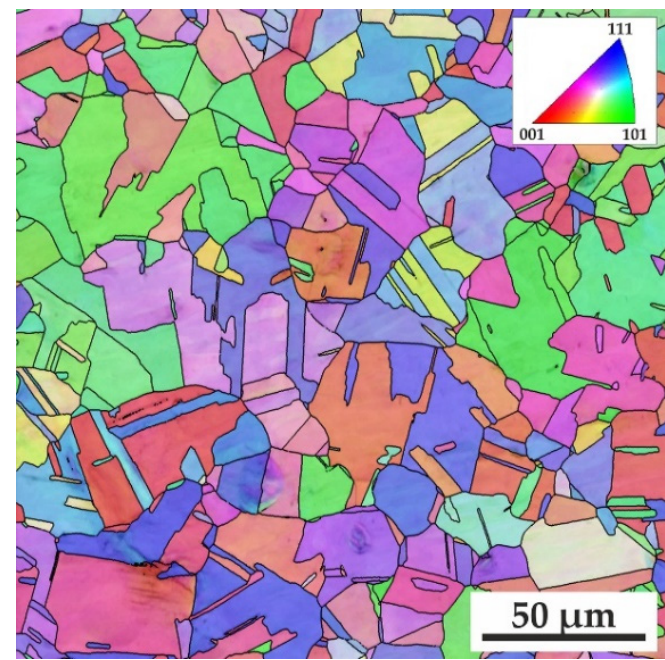

(b)

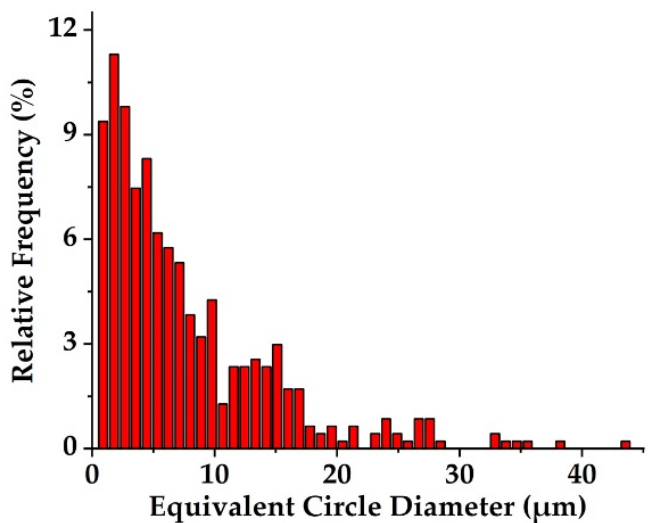

(d)

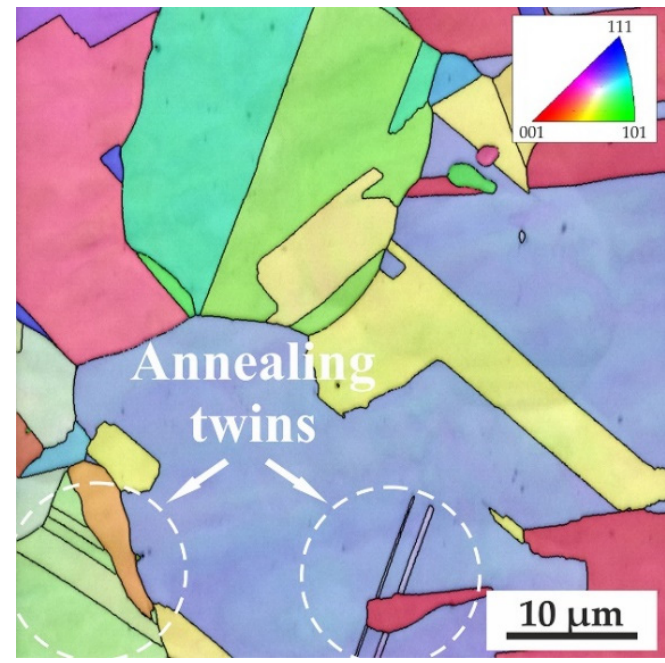

(f)

Figure 2. SEM Electron backscatter diffraction (EBSD) images of the steel solution-treated microstructure. Phase map, where austenite is in blue color, carbides is in red color, high-angle, and twin boundaries are denoted by black and red lines, respectively $(\mathbf{a}, \mathbf{e})$; orientation map $(\mathbf{b}, \mathbf{f})$, grain misorientation distribution $(\mathbf{c})$, grain sizes distribution $(\mathbf{d})$. The arrows indicate fine and coarse carbides of MX type (e) and annealing twins (f). 
Thin foils in the sections perpendicular to TD were studied by TEM methods. It was shown that HTMT-1 leads to the grain fragmentation and the formation of numerous new low-angle boundaries. As a result, the plates with curved boundaries, which are elongated in the rolling direction, are formed inside the austenitic grains (Figure 3a). Their widths can be up to several microns. The plates have low-angle misorientation boundaries (Figure $3 b$ ). It should be noted that in some areas of the microstructure, there are regions with predominantly equiaxed subgrains with dimensions of $\approx 1 \mu \mathrm{m}$ (Figure $3 \mathrm{c}$ ). In addition, accumulations of MX-type particles were detected in these areas.

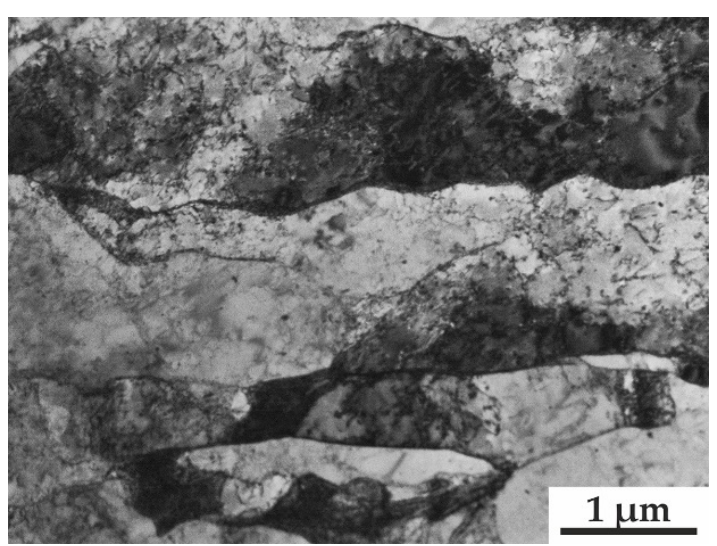

(a)

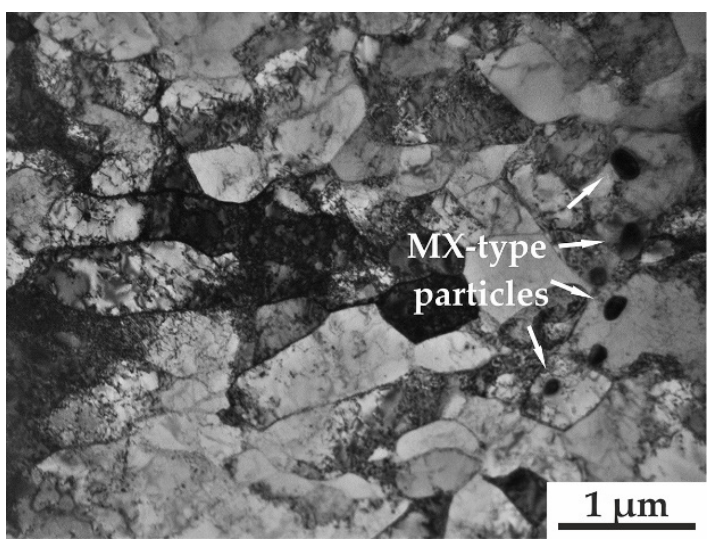

(c)

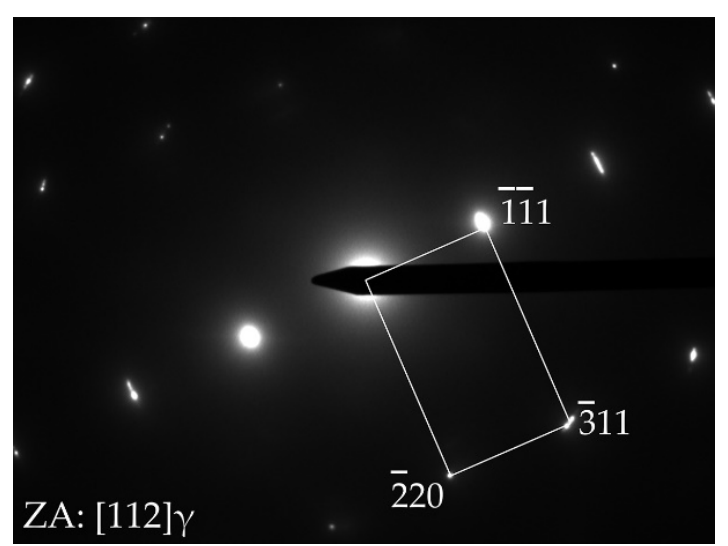

(b)

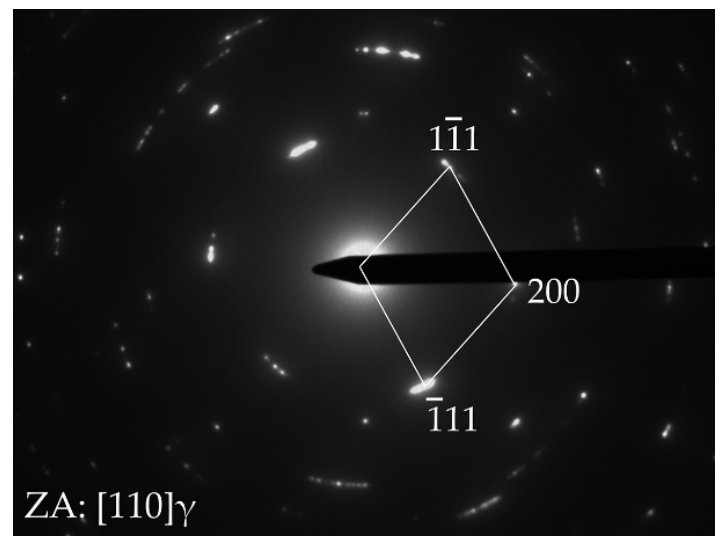

(d)

Figure 3. Transmission electron microscopy (TEM) images of steel microstructure after HTMT-1. Bright-field (BF) image (a), selected area electron diffraction (SAED) pattern with marked zone axis [112] $\gamma(\mathbf{b})$, BF image with MX particles marked by arrows (c), SAED pattern with marked zone axis (ZA) $[110] \gamma(\mathbf{d})$.

HTMT-2 contributes to an increase in the dislocation density inside the fragmented plates (Figure 4a). An analysis of the diffraction pattern reveals the presence of low-angle and high-angle misorientation boundaries between the fragmented plates (Figure $4 \mathrm{~b}$ ). In addition, the diffraction pattern contains low- and high-angle misorientation boundaries between the fragmented plates (Figure $4 \mathrm{~b}$ ). The presence of the latter is evidenced by the presence in the diffraction pattern of two zone axes of [110] and [001], the misorientation between them being as large as $45^{\circ}$. Figure $4 \mathrm{c}$ shows a typical microstructure consisting of several plates with high- and low-angle misorientation boundaries. In the center, there is a plate with a width of $\approx 1.5$ microns with an internal subgrain structure having low-angle misorientation boundaries. On the left and right, this plate has high-angle misorientation boundaries with thinner plates (wide $\approx 400-500 \mathrm{~nm}$ ). Fine particles of the MX type were found in the grain volume. 


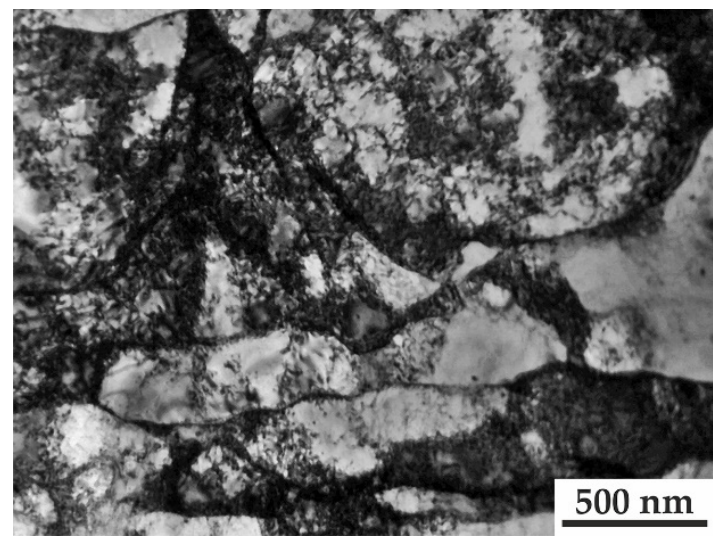

(a)

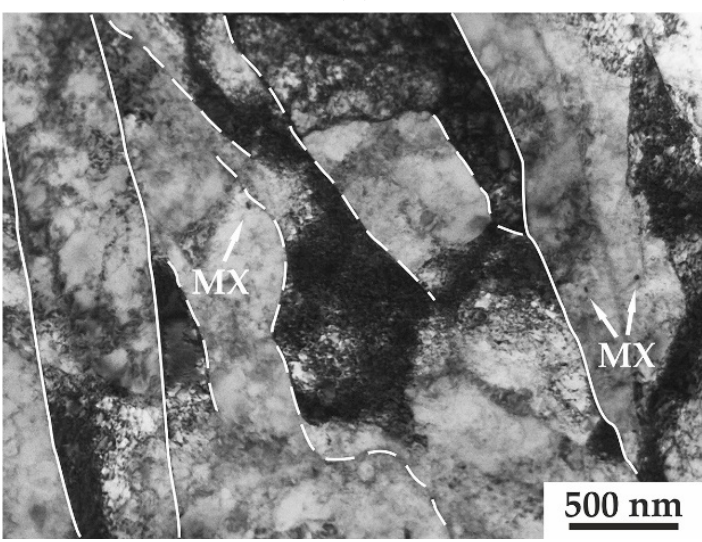

(c)

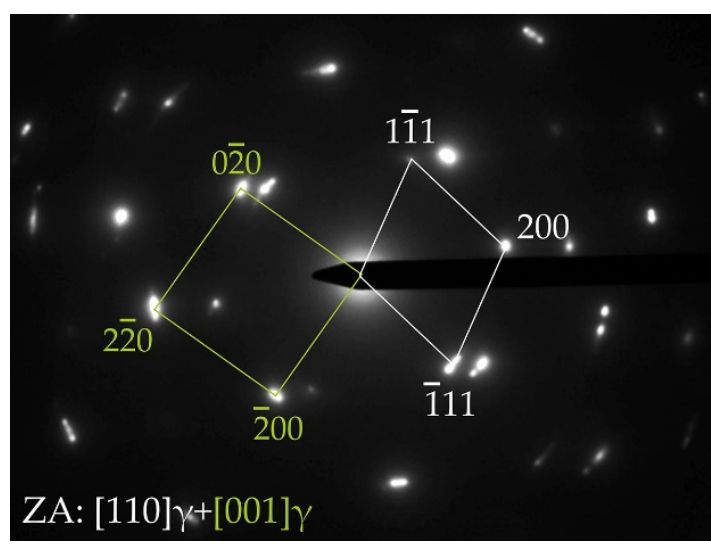

(b)

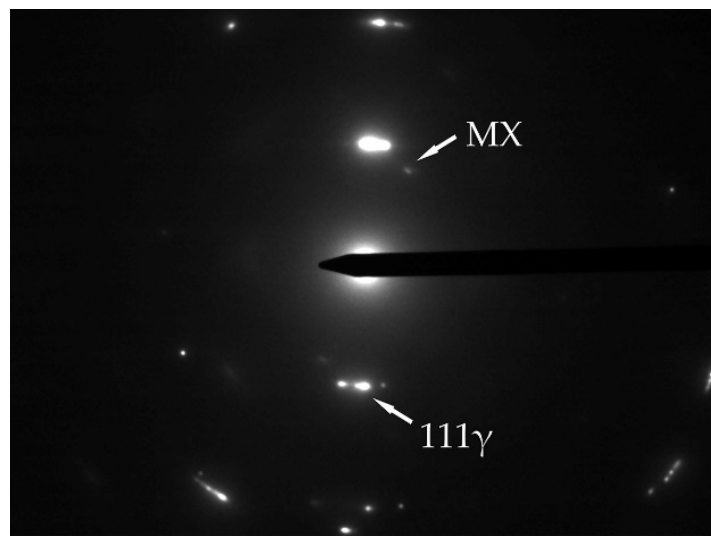

(d)

Figure 4. TEM images of steel microstructure after HTMT-2. BF images with fragmented structure $(\mathbf{a}, \mathbf{c})$, SAED patterns $(\mathbf{b}, \mathbf{d})$. Two zone axes-[110] $\gamma$ and $[001] \gamma$ are marked on $(\mathbf{b})$. Solid lines on (c) indicate high-angle boundaries, dashed lines-low-angle.

The microstructure of steel after HTMT-3 in two sections perpendicular to TD and ND was investigated by EBSD methods. It has been shown that HTMT-3 leads to significant grain refinement in the section perpendicular to TD (Figure 5a). The average grain size is $\approx 1.8 \mu \mathrm{m}$. Austenitic grains have a specific shape-elongated plates. Their length can reach $\approx 100 \mu \mathrm{m}$. On the phase map among the fragmented plates, individual large particles of the MX type can be seen (Figure $5 b$ ). The fraction of special type $\Sigma 3$ boundaries (annealing twins) decreases to less than $1 \%$. This is due to the high $(e=2)$ strain degree at the elevated temperatures. In this case, the initial boundaries of the annealing twins become the arbitrary type boundaries. The fraction of high-angle boundaries is $\approx 44.8 \%$, and that of low-angle boundaries is $\approx 55.2 \%$ (Figure 5 c). The histogram of grain size distribution (Figure $5 \mathrm{~d}$ ) shows that the structure mainly contains grains up to $5 \mu \mathrm{m}$ in size, but there are also individual grains of $\approx 20 \mu \mathrm{m}$. It should be noted that the fine grains are located along the elongated coarse grains (Figure 5a). In the images with high magnification (Figure 5e,f) MX particles with a size of $\leq 1 \mu \mathrm{m}$ were detected. They are located mainly along the grain boundaries. 


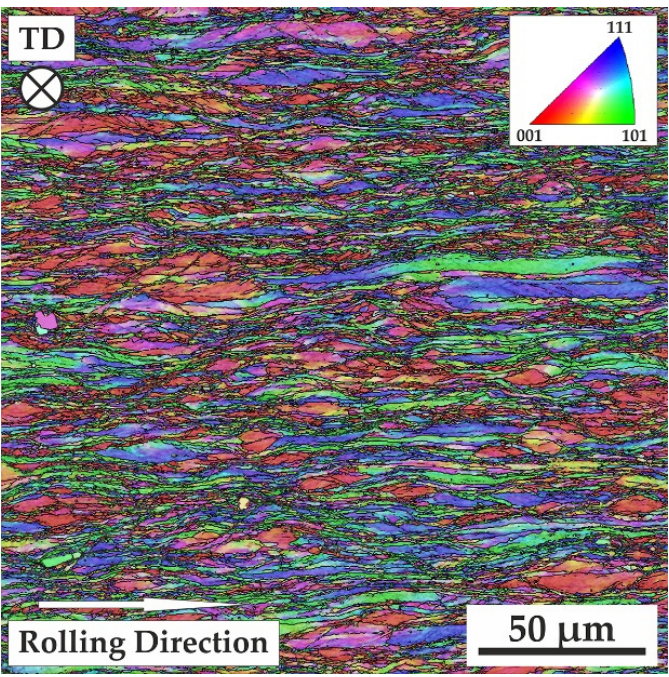

(a)

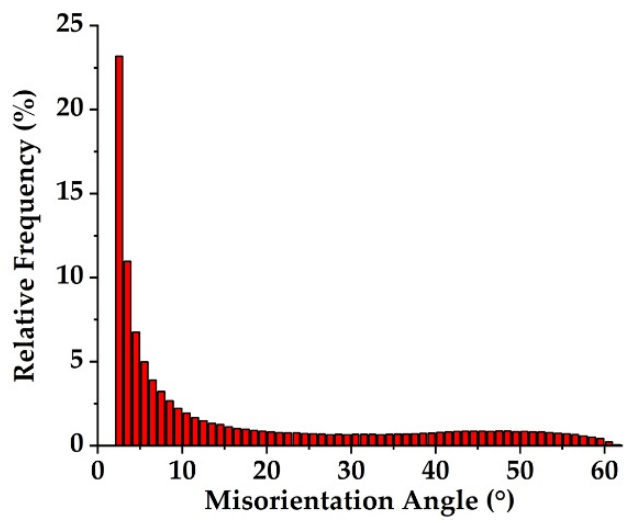

(c)

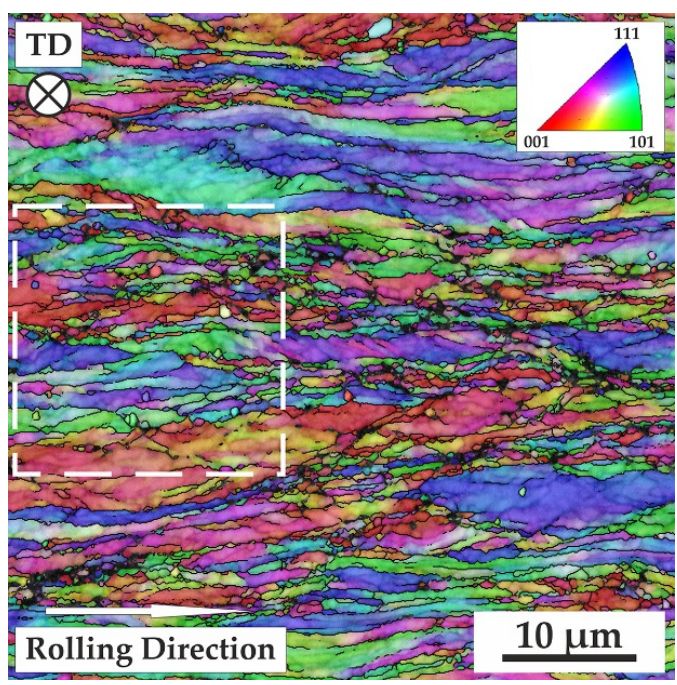

(e)

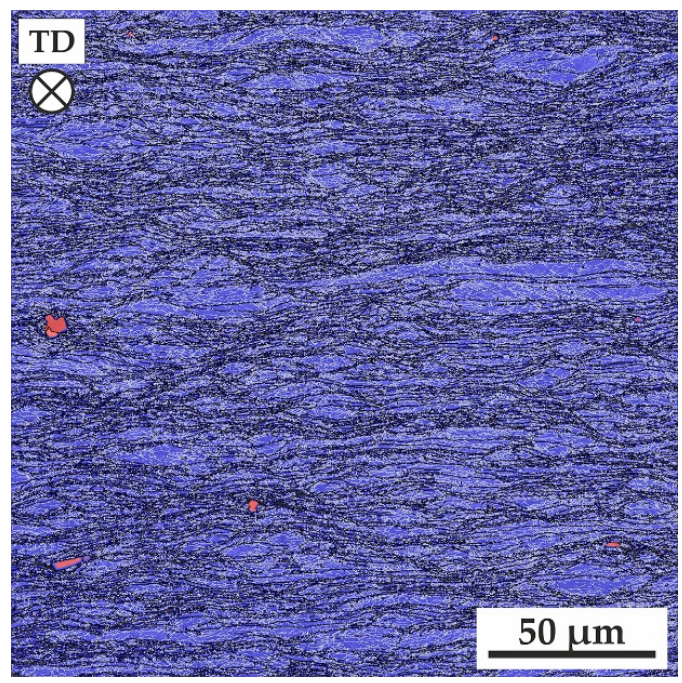

(b)

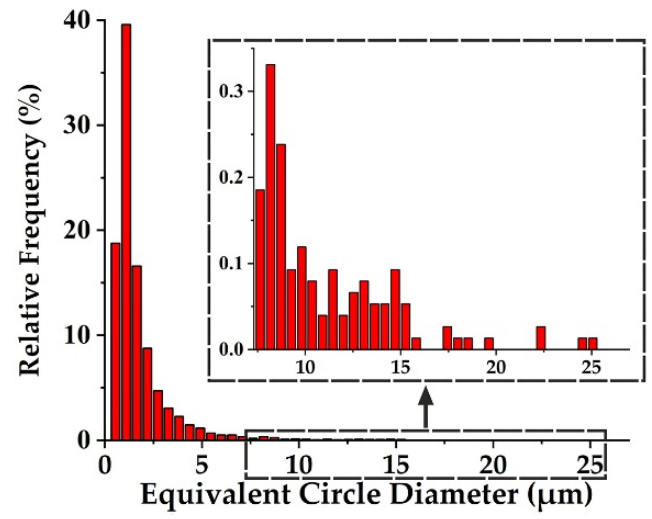

(d)

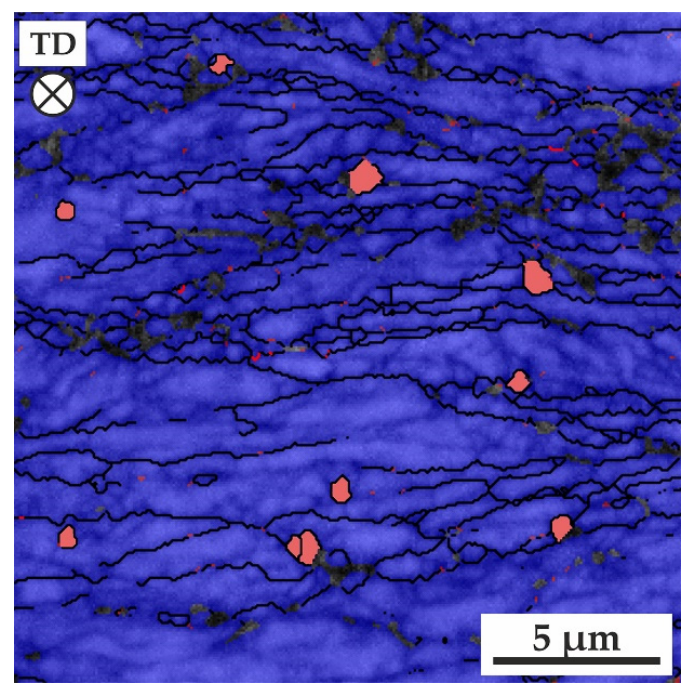

(f)

Figure 5. SEM EBSD images of steel microstructure after HTMT-3 in the section perpendicular to transverse direction (TD). Orientation map (a), phase map, where austenite is in blue color, carbides is in red color with high-angle and low-angle misorientation boundaries denoted by black and white lines, respectively (b), grain misorientation distribution $(\mathbf{c})$, grain size distribution $(\mathbf{d})$, orientation map (e), phase map with the area of the structure marked on (e) image by a dashed-line square (f). Austenite is in blue color, carbides is in red color with high-angle boundaries denoted by black lines. 
After HTMT-3, in the section perpendicular to ND, the fragmented microstructure consists of grains with sizes of tens of micrometers and grains with sizes up to $5 \mu \mathrm{m}$ (Figure 6a). The volume fraction of these grains is 5 and $95 \%$, respectively. The average grain size (as in the section perpendicular to TD) is $\approx 1.8 \mu \mathrm{m}$. At the same time, coarse grains (up to $74 \mu \mathrm{m}$ ) were found, the dimensions of which exceed the maximum size in the ST state. This is due to the flattened shape of the grains in the rolling plane and elongated shape in the rolling direction. Multiple low-angle boundaries (Figure $6 \mathrm{~b}$ ) and clusters of fine grains (up to $5 \mu \mathrm{m}$ ) were found inside the coarse grains. The histogram of the grain misorientation distribution (Figure 6c) shows that the fraction of high-angle boundaries decreases (down to $19.8 \%$ ) and that of low-angle ones increases (up to $80.2 \%$ ) compared to the section perpendicular to TD.

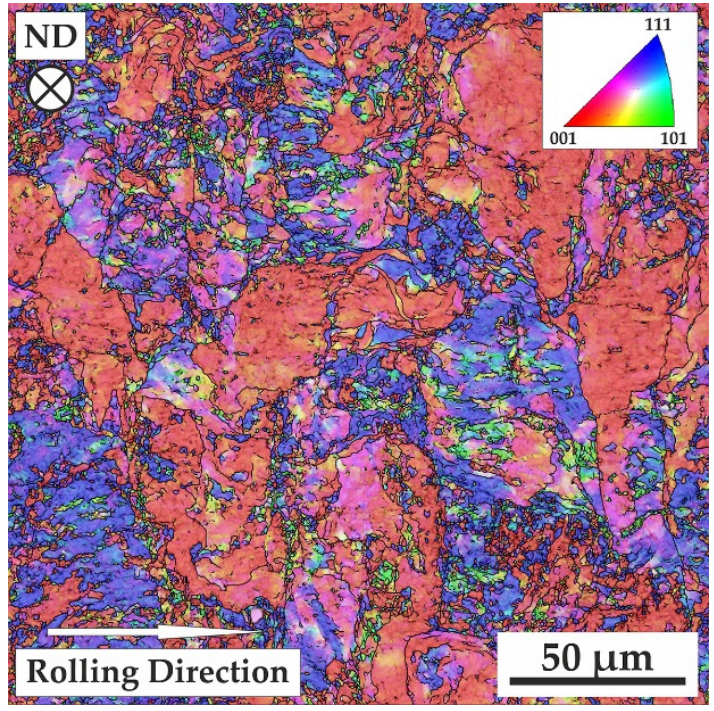

(a)

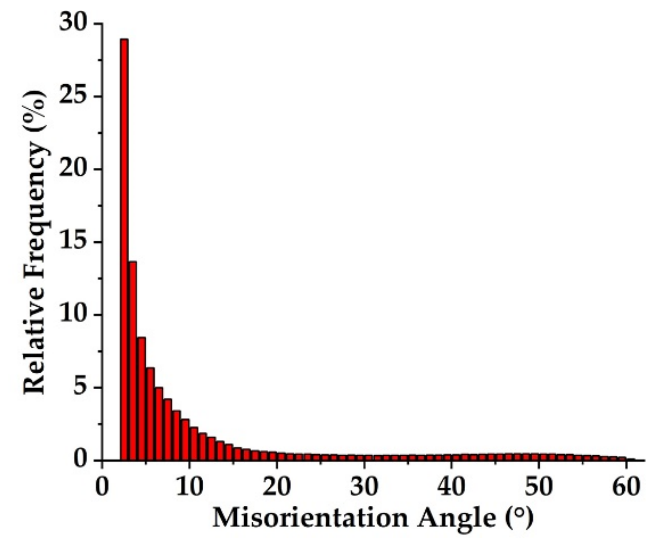

(c)

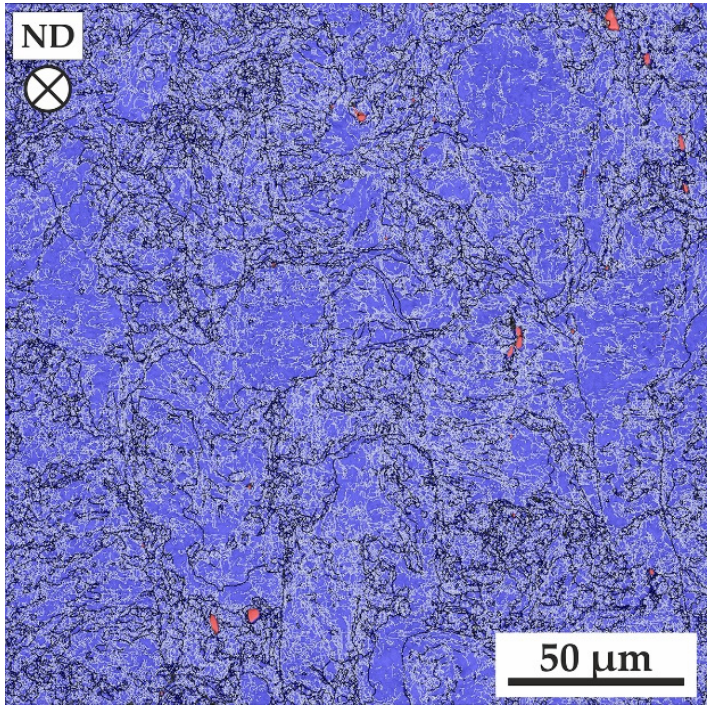

(b)

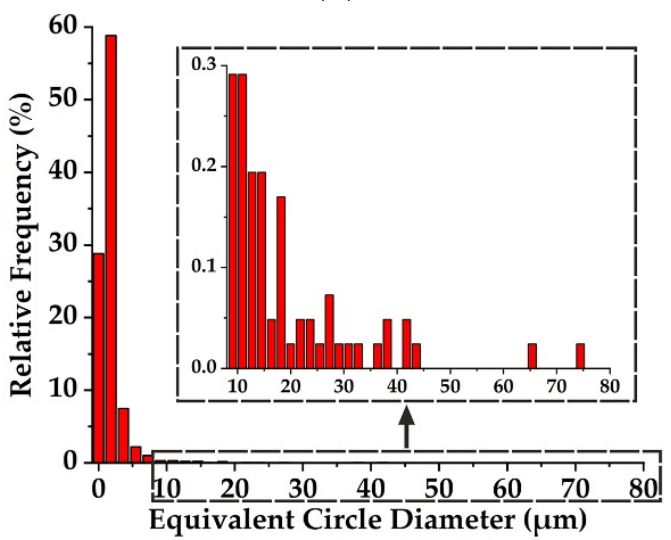

(d)

Figure 6. SEM EBSD images of steel microstructure after HTMT-3 in the section perpendicular to normal direction (ND). Orientation map (a), phase map, where austenite is in blue color, carbides is in red color with high-angle and low-angle boundaries are denoted by black and white lines, respectively (b), grain misorientation distribution (c), grain sizes distribution (d).

It is shown by TEM that after HTMT-3 in the section perpendicular to TD the minimum width of the elongated plates is less than $200 \mathrm{~nm}$. Between the plates (Figure 7a) both low-angle and high-angle misorientation boundaries are observed. This follows from the analysis of the SAED pattern, which shows two axes of the zone [110] $\gamma$ with a misorientation of $60^{\circ}$ (Figure $7 \mathrm{~b}$ ). 


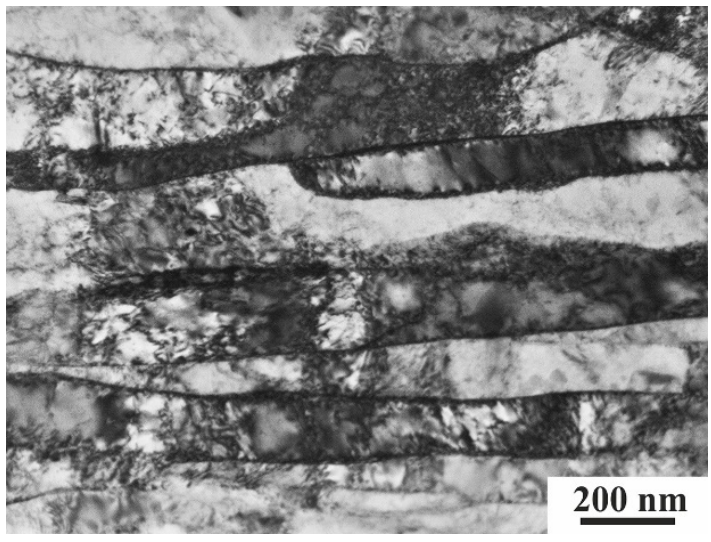

(a)

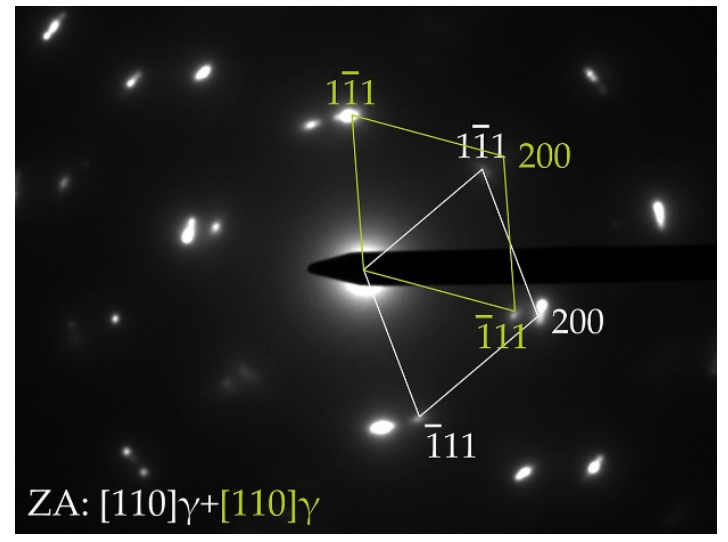

(b)

Figure 7. TEM images of steel microstructure after HTMT-3 in the section perpendicular to TD. BF image with fragmented plates (a), SAED patterns with marked two [110] $\gamma$ zone axes (b).

The subsequent cold deformation (after HTMT-3) leads to intensive mechanical twinning. STEM techniques show that deformation microtwins are formed in a significant volume of the material, including the fragmented plates (Figure 8a). Many fragmented plates are filled by nanotwin packets (Figure $8 \mathrm{~b}$ ). Note that low-angle boundaries are not obstacles for microtwins propagation (Figure 8c). Microtwins in these plates are observed on several twinning planes. A characteristic azimuthal twisting of the reflections (Figure 8d) was detected on the corresponding SAED pattern. This is due to the numerous low-angle misorientation boundaries resulting from HTMT-3 + CR. In addition, there are extended reflections in diffraction patterns due to the presence of thin nanoscale twin plates (Figure 8c). No mechanical twinning is detected in plates narrower than $100 \mathrm{~nm}$. Basically, such plates lie between wide plates with an internally twinned structure.

It should be noted that the formation of new MX particles during multistage HTMT was not detected by structural investigations.

\subsection{Mechanical Properties}

The results of investigation of the steel mechanical properties in the ST state and after each HTMT stage are presented in Table 2 and Figure 9. In the ST state at $20{ }^{\circ} \mathrm{C}$, characteristic mechanical properties for austenitic steel are observed (Table 2). At an elevated tensile temperature $\left(650{ }^{\circ} \mathrm{C}\right)$ in this state, the yield strength is $\approx 95 \mathrm{MPa}$, the elongation to fracture is $\approx 31 \%$. HTMT- 1 leads to an increase in strength-the yield strength increases by $\approx 225 \mathrm{MPa}\left(\right.$ at $20^{\circ} \mathrm{C}$ ) and $\approx 200 \mathrm{MPa}\left(\right.$ at $650{ }^{\circ} \mathrm{C}$ ). In this case, the elongation to fracture decreases by a factor of 2 both at $20^{\circ} \mathrm{C}$ and $650{ }^{\circ} \mathrm{C}$. Subsequent HTMT-2 and HTMT-3 contribute to a further strengthening of the steel-the yield strength increases up to $765 \mathrm{MPa}$ (at $20 \mathrm{C}$ ) and up to $520 \mathrm{MPa}\left(\right.$ at $650{ }^{\circ} \mathrm{C}$ ). An increase in strength properties is accompanied by a decrease in the values of elongation to failure-to $7.8 \%$ and $4.5 \%$, respectively (Table 2). These changes in the mechanical properties are associated with the formation of elongated and flattened austenite grains, the average size of which decreases by a factor of 4.3 compared to the ST state. In addition, note that the resulting fragmented structure with numerous low-angle misorientation boundaries (up to $\approx 80 \%$ in the section perpendicular to ND) plays a key role in strengthening of the material. 


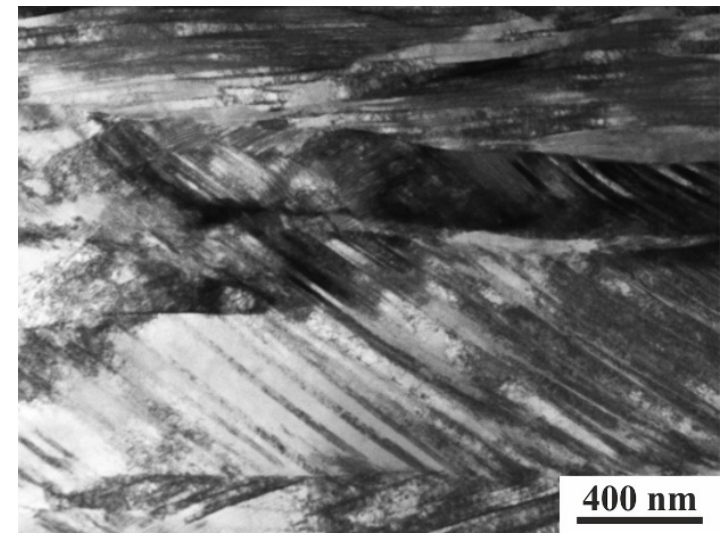

(a)

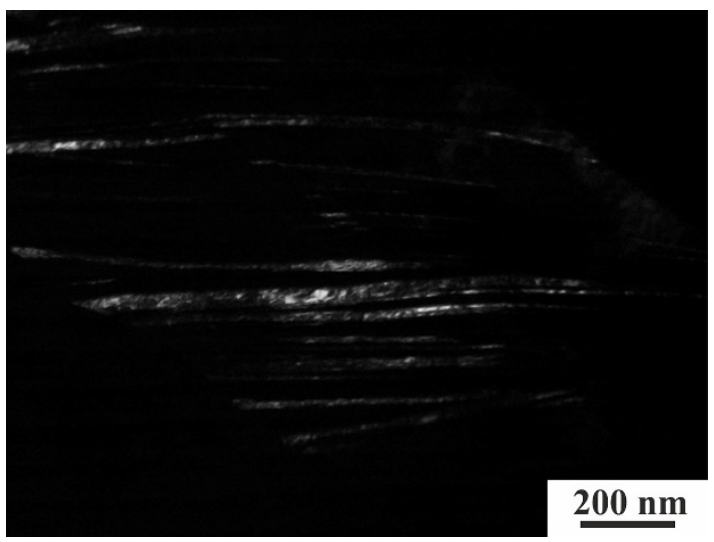

(c)

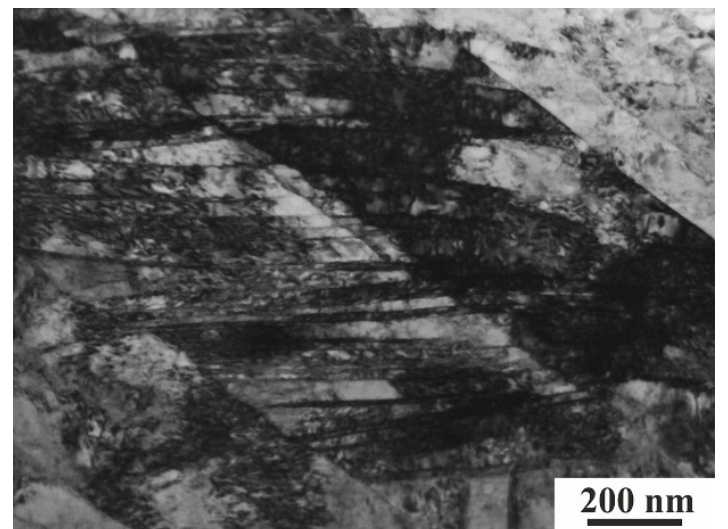

(b)

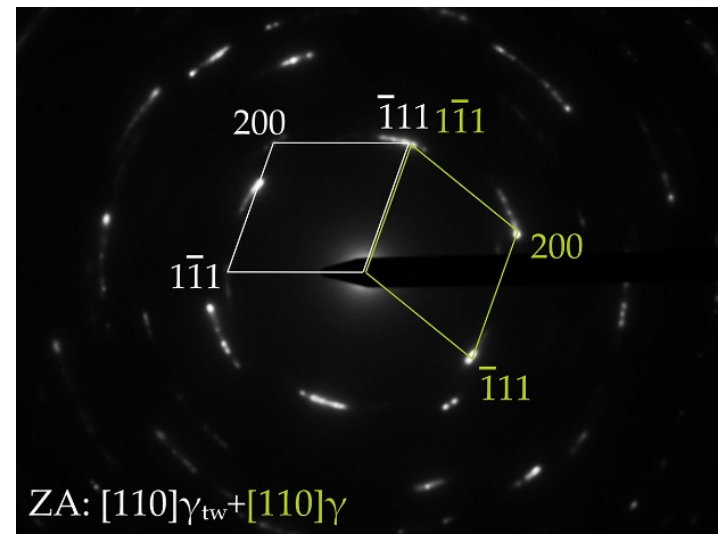

(d)

Figure 8. STEM and TEM images of steel microstructure after HTMT-3 + CR in the section perpendicular to TD. STEM image of fragmented structure with micro and nanotwins (a); BF image with fragmented plates and nanotwins (b), Dark-field image in $\mathrm{g}=1-11 \gamma_{\mathrm{tw}}$ (c); SAED patterns with matrix zone axis [110] $\gamma$ marked by yellow color and twin zone axis [110] $\gamma_{\mathrm{tw}}$-by white color (d).

Table 2. Mechanical Properties of EK-164 Steel.

\begin{tabular}{ccccc}
\hline Treatment & Temp. Tensile Tests, $^{\circ} \mathbf{C}$ & YS, MPa & TS, MPa & El., \% \\
\hline \multirow{2}{*}{ ST } & 20 & $201.4 \pm 2$ & $539.2 \pm 9.6$ & $47.4 \pm 0.1$ \\
& 650 & $95 \pm 6.3$ & $360.2 \pm 8.8$ & $31 \pm 1.6$ \\
\hline \multirow{2}{*}{ HTMT-1 } & 20 & $425.8 \pm 16.8$ & $598 \pm 0.4$ & $23.4 \pm 0.7$ \\
& 650 & $297.3 \pm 42.7$ & $431.3 \pm 5.9$ & $16.3 \pm 4.1$ \\
\hline \multirow{2}{*}{ HTMT-2 } & 20 & $642.9 \pm 21.1$ & $731.5 \pm 16.8$ & $11.4 \pm 1.1$ \\
& 650 & $472.7 \pm 22.3$ & $522.2 \pm 1.6$ & $4.5 \pm 1$ \\
\hline \multirow{2}{*}{ HTMT-3 } & 20 & $764.8 \pm 1.6$ & $859.9 \pm 12.2$ & $7.8 \pm 0.4$ \\
& 650 & $521 \pm 17.7$ & $589.8 \pm 39.3$ & $4.8 \pm 0.7$ \\
\hline \multirow{2}{*}{ HTMT-3 + CR } & 20 & $911.9 \pm 25$ & $1041.4 \pm 34.7$ & $5.4 \pm 0.6$ \\
& 650 & $580.2 \pm 5.2$ & $706.5 \pm 39.9$ & $6.1 \pm 2.1$ \\
\hline
\end{tabular}




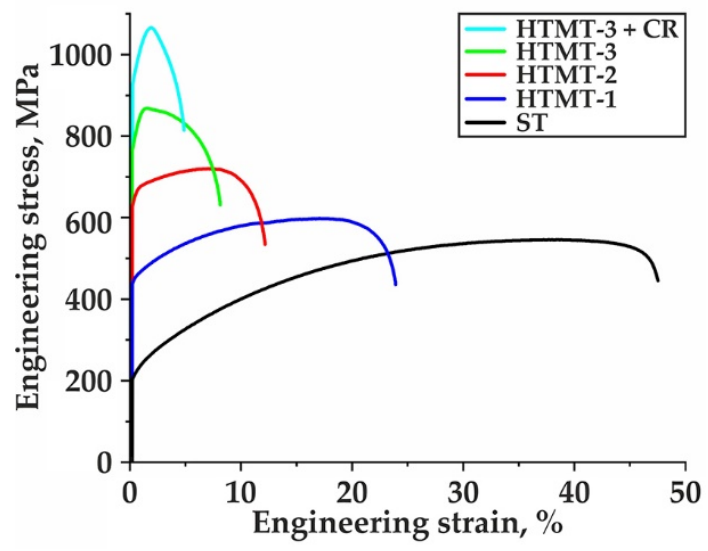

(a)

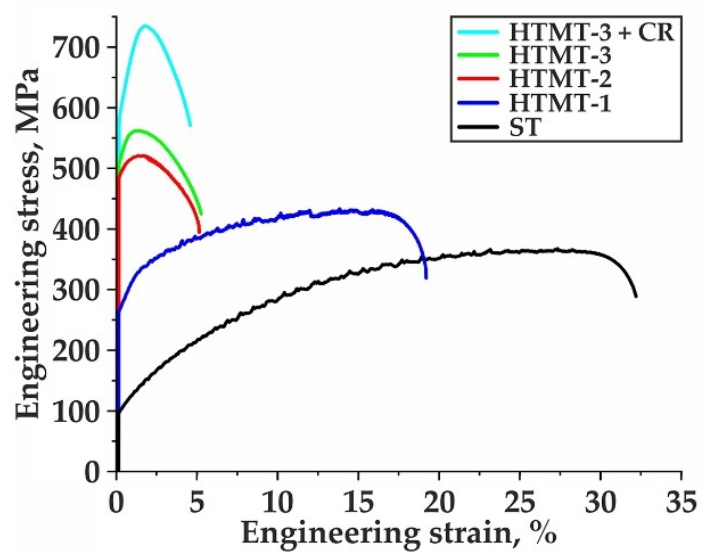

(b)

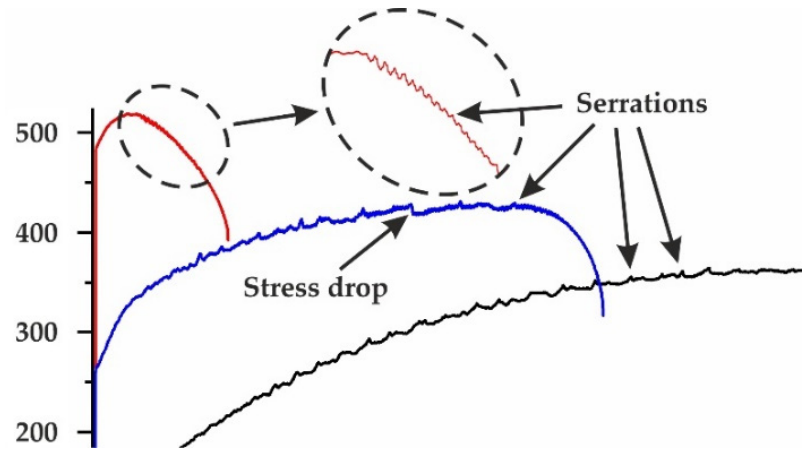

(c)

Figure 9. Engineering stress-engineering strain curves of some treated steel samples: tension at 20 (a), tension at $650{ }^{\circ} \mathrm{C}(\mathbf{b})$, magnified part of curves from the image (b) with serration flow (c).

Cold deformation after HTMT-3 due to the development of multiple twinning inside the fragmented plates contributes to additional steel strengthening. The above microstructure provides the maximum values of strength properties both at a tensile temperature of $20{ }^{\circ} \mathrm{C}$ (yield strength $\approx 910 \mathrm{MPa}$ ) and at $650{ }^{\circ} \mathrm{C}$ (yield strength $\approx 580 \mathrm{MPa}$ ). The retention of high values of strength properties at an elevated tensile temperature is associated with the high thermal stability of deformation twins. According to the in-situ studies [20], microtwins are capable of surviving in the structure of austenitic steels up to $1000{ }^{\circ} \mathrm{C}$ with a holding time of up to $37 \mathrm{~min}$. The high density of microtwins after HTMT-3 + CR contributes to a significant decrease in the elongation to failure down to $\approx 5-6 \%$.

Strain curves at $20^{\circ} \mathrm{C}$ in the ST state, as well as after HTMTs, are monotonic without any features (Figure 9a). Thermomechanical treatments lead to an increase in the tensile strength and yield strength and a decrease in the plastic properties. At elevated tensile temperature $\left(650^{\circ} \mathrm{C}\right)$ in the ST state, as well as after HTMT-1 and HTMT-2, regions with serrated plastic flow were found in the curves (Figure 9b). In the ST state and after HTMT-1, these regions are observed practically along the entire length of the flow curves. These features of the curves are associated with the dynamic strain aging (DSA). After HTMT-2, this phenomenon is observed on a narrow segment of the curve. The increase in the yield and tensile strengths at high temperatures after HTMT-3 relative to HTMT-2 is insignificant $(\Delta \sigma \approx 50-70 \mathrm{MPa})$ compared to similar values at $20^{\circ} \mathrm{C}$. No serrated flow is detected after HTMT-3. In addition, the elongation to failure after these treatments decreases down to $\approx 5 \%$, which is comparable to the corresponding value after additional cold deformation (Figure 9). These features indicate the suppression of DSA in severely deformed structural states. 


\section{Discussion}

\subsection{Grain Refinement and Substructure Formation}

Microstructural evolution of EK-164 steel under multistage HTMT (total strain of $e \approx 2$ ) is typical for fcc steels with low and medium stacking fault energies, deformed at different temperatures $[13,14,21]$. With an increase in the degree of deformation the dislocation density increases, and new low- and high-angle misorientation boundaries are formed. Hot and warm rolling deformation promotes fragmentation and a change of the shapes of austenite grains. With a decrease in the deformation temperature, the fragmentation of grains occurs more intensively, as in $[13,22]$. As a result, during HTMT, the initial equiaxed grains become elongated in the rolling direction (Figure 5) and flattened in the rolling plane (Figure 6). This microstructure is called pancake grain structure or pancaked grains [12,21]. Fine grains are found in the volume of large coarse grains and along their boundaries (Figure 6b). It is shown by Belyakov A. et al. [13,22,23] and Huang L. et al. [24,25] that under thermomechanical treatments in the temperature range of $500-1100{ }^{\circ} \mathrm{C}$ at high strain rates and degrees $(e \geq 2)$ DRX develops in austenitic steels. It is noted that at higher deformation temperatures, the formation of DRX grains occurs more intensively. In this work, the formation of DRX grains is suppressed, since warm deformation (HTMT-3), that completes the HTMT sequence, occurs at a temperature much lower than that required for the nucleation of DRX grains. It is assumed that the formation of fine grains is associated with deformation grain refinement due to a high total strain degree. Subsequent cold deformation $(e=0.3)$ promotes additional fragmentation of the structure due to mechanical twinning. At low deformation temperatures in austenitic steels with low and medium stacking fault energies, mechanical twinning is a deformation mechanism competing with the dislocation slip $[9,20,26]$. As a result, a high density of deformation micro- and nanotwins is formed inside the elongated grains.

\subsection{Comparison of Mechanical Properties}

It should be noted that the achieved mechanical properties of EK-164 steel after multistage HTMT are comparable with the properties presented in $[13,15]$ on other austenitic steels. It is shown [13] that the yield strength reaches $875 \mathrm{MPa}$ (at $20^{\circ} \mathrm{C}$ ), $580 \mathrm{MPa}$ (at $\left.600{ }^{\circ} \mathrm{C}\right)$, and $430 \mathrm{MPa}\left(\right.$ at $700{ }^{\circ} \mathrm{C}$ ) after HTMT with plastic deformation at $700{ }^{\circ} \mathrm{C}$ with a total strain degree of $e=2$. At this deformation temperature, DRX is realized in steel. In this case, the elongation to failure decreases (from 10 to $5 \%$ ) with a change in the tensile temperature from 20 to $700{ }^{\circ} \mathrm{C}$. The authors note that DSA is not observed in this case. In [15], HTMT with a sequence of hot and warm deformation (total deformation $e \approx 1.5$ ) leads to an increase in the yield strength up to $677 \mathrm{MPa}$, while maintaining the elongation to fracture $\approx 12 \%$ at $20{ }^{\circ} \mathrm{C}$.

In the present study, the values of the yield strength achieved after HTMT-3 are close to those indicated in [13] and are significantly higher than that in [15]. The latter is associated with a lower degree of deformation and, as a consequence, less fragmented substructure.

\subsection{Dynamic Strain Aging during Tensile Tests at $650{ }^{\circ} \mathrm{C}$}

The phenomenon of dynamic strain aging consists in the precipitation of dispersed particles during deformation at elevated temperatures and is a consequence of the interaction between the solute atoms and the movable dislocations during tensile plastic deformation [27-29]. This phenomenon is also called the Portevin-Le Chatelier effect. It is known that DSA develops in the structure due to the generation of new dislocations that are involved in the deformation process. Such dislocations move until they encounter with impurity atoms. This is accompanied by blocking of dislocations and an increase in tensile stresses, which contributes to the nucleation of new dislocations. As soon as there are enough new dislocations, the process of further plastic flow starts. As a result, serrations are formed on the flow curve.

The main factors affecting DSA are strain rate, temperature, chemical composition, etc. [27-29] Figure 9b shows that a serrated flow is observed on some tensile curves at 
elevated test temperatures. This type of serrations, which are characterized by a sharp increase in stress, alternating with a plateau, is referred to as type A serration, according to the classification of Rodriguez [30]. This behavior is associated with tension at a relatively high strain rate $\approx 2 \times 10^{-3} \mathrm{~s}^{-1}$. Earlier [31], it was shown that tensile tests of EK-164 steel samples in the ST state leads to the development of DSA processes in the temperature range of $400-650^{\circ} \mathrm{C}$. At the same time, with an increase in the deformation temperature, the density and intensity of the peaks on the tensile curves increase. In [12] it was shown on AISI 310 steel under tension in the temperature range of $800-1100{ }^{\circ} \mathrm{C}$ that during DSA complex carbides are formed (based on $\mathrm{Cr}, \mathrm{Mo}, \mathrm{Ni}, \mathrm{Fe}$ ) located along grain boundaries. Sun H. et al. [12] argue that precipitation is caused by the effect of the applied stress.

In the present work, in the ST state and after HTMTs, the DSA effect is observed on the tensile curves at $650{ }^{\circ} \mathrm{C}$, from the very beginning of plastic flow. The difference in these curves is that after HTMT-1 there is a section with a stress drop (Figure 9c), during which the dislocation motion is unblocked. The high-angle misorientation boundaries created during processing serve as barriers to the dislocation motion, and with an increase in the density of these boundaries, the DSA effect is suppressed. After HTMT-2, the DSA effect on the stress-strain curve is observed only in the stage of neck formation and is short. In this state, the density of dislocations and low- and high-angle boundaries is higher and, therefore, the number of barriers to the motion of movable dislocations becomes larger. As a result, the plastic part of the flow curve is significantly reduced. No DSA effect is detected after HTMT-3 and HTMT-3 + CR for the same reason. Thus, the deformation structure and substructure formed during HTMTs have a decisive influence on the development of DSA processes during tensile testing of EK-164 steel.

\section{Conclusions}

In this paper, the effect of multistage HTMT with plastic deformation with the temperature decreasing in each stage $\left(1100,900\right.$, and $600{ }^{\circ} \mathrm{C}$ with a total strain degree of $\left.e=2\right)$ on the microstructure and mechanical properties of the EK-164 austenitic reactor steel has been investigated. The main results can be summarized as follows:

1. Under HTMTs, structural states with the pancake grain structure are formed, which is characterized by grains elongated in the rolling direction and flattened in the rolling plane. The average grain size is $1.8 \mu \mathrm{m}$, which is $10.7 \mu \mathrm{m}$ less than in the ST. A high density of low-angle boundaries up to $\approx 80 \%$ (in the section perpendicular to ND) and up to $\approx 55 \%$ (in the section perpendicular to TD) was found inside the fragmented grains.

2. Additional cold deformation with $e=0.3$ (after HTMTs) allows the creation of a high density of micro- and nanotwins of deformation in fragmented grains. Low-angle boundaries are not obstacles for microtwins propagation. At the same time, coarse and finely dispersed particles of the MX type are preserved without their additional precipitation after all treatments.

3. The tensile tests at a strain rate of $\sim 10^{-3} \mathrm{~s}^{-1}$ showed that the obtained microstructure provides high strength properties of steel: yield strength $\approx 580 \mathrm{MPa}$ and $910 \mathrm{MPa}$, tensile strength $\approx 700 \mathrm{MPa}$ and $1040 \mathrm{MPa}$ at $650{ }^{\circ} \mathrm{C}$ and $20^{\circ} \mathrm{C}$, respectively.

4. At elevated tensile temperatures, serrated flow is observed on the curves due to the DSA effect. The high density of low and high angle boundaries formed as a result of HTMT-3 and HTMT-3 + CR inhibits the dislocation motion and suppresses the DSA effect during tensile tests.

Thus, multistage HTMT (with a total strain degree of $e \approx 2.3$ ) is an effective method for forming a deformed substructure and increasing the strength of the austenitic reactor steel.

Author Contributions: Conceptualization, S.A. and I.L.; methodology, S.A.; investigation, S.A., N.P., K.A. and E.M.; writing-original draft preparation, S.A.; writing—review and editing, I.L. and S.A.; visualization, S.A. and A.K.; supervision, V.C.; project administration, I.L. All authors have read and agreed to the published version of the manuscript. 
Funding: The work was performed according to the Government Research Assignment for the Institute of Strength Physics and Materials Science of the Siberian Branch of the Russian Academy of Sciences (ISPMS SB RAS), project No. FWRW-2021-0008.

Institutional Review Board Statement: Not applicable.

Informed Consent Statement: Not applicable.

Data Availability Statement: Not applicable.

Acknowledgments: The investigations have been carried out using the equipment of the Tomsk Materials Research Share Use Centre, the Share Use Centre "Analytical Center for Geochemistry of Natural Systems" of Tomsk State University and the Share Use Centre "Nanotech" of the Institute of Strength Physics and Materials Science SB RAS.

Conflicts of Interest: The authors declare no conflict of interest.

\section{The List of Nomenclature:}

$\begin{array}{ll}\text { HTMT } & \text { high-temperature thermomechanical treatment } \\ e & \text { true strain degree } \\ \text { SEM } & \text { scanning electron microscopy } \\ \text { EBSD } & \text { electron backscatter diffraction } \\ \text { TEM } & \text { transmission electron microscopy } \\ \text { ST } & \text { solution treatment } \\ \text { DRX } & \text { dynamic recrystallization } \\ \text { HR } & \text { hot rolling deformation } \\ \text { WR } & \text { warm rolling deformation } \\ \text { CR } & \text { cold rolling deformation } \\ \text { ND } & \text { normal direction } \\ \text { TD } & \text { transverse direction } \\ \text { STEM } & \text { scanning transmission electron microscopy } \\ \Sigma 3 & \text { special boundaries of misorientation angle } \\ \text { ZA } & \text { zone axis } \\ \gamma & \text { austenite } \\ \text { BF } & \text { bright-field image } \\ \text { SAED } & \text { selected area electron diffraction } \\ \gamma \text { tw } & \text { mechanical twins of austenite } \\ \text { YS } & \text { yield strength } \\ \text { TS } & \text { tensile strength } \\ \text { El. } & \text { elongation to failure } \\ \text { DSA } & \text { dynamic strain aging }\end{array}$

\section{References}

1. Yvon, P. Structural Materials for Generation IV Nuclear Reactors; Elsevier: Amsterdam, The Netherlands, 2017 ; ISBN 9780081009062. [CrossRef]

2. Garner, F.A. Radiation-induced damage in austenitic structural steels used in nuclear reactors. In Comprehensive Nuclear Materials, 2nd ed.; Konings, R.J.M., Stoller, R.E., Eds.; Elsevier: Amsterdam, The Netherlands, 2020; Volume 3, pp. 57-168. [CrossRef]

3. Odette, R.G.; Zinkle, S.J. Structural Alloys for Nuclear Energy Applications; Elsevier: Amsterdam, The Netherlands, 2019; ISBN 9780123970466. [CrossRef]

4. Kozlov, A.; Kozlov, K.; Portnykh, I. The evolution of helium-vacancy bubbles in austenitic steels under neutron irradiation. J. Nucl. Mater. 2021, 549, 152915. [CrossRef]

5. Portnykh, I.A.; Kozlov, A.V.; Panchenko, V.L.; Mitrofanova, N.M. Characteristics of radiation porosity formed upon irradiation in a BN-600 reactor in the fuel-element cans of cold-deformed steel EK-164 (06Kh16N20M2G2BTFR)-ID c.d. Phys. Met. Metallogr. 2012, 113, 520-531. [CrossRef]

6. Portnykh, I.A.; Kozlov, A.V.; Panchenko, V.L. Effect of dose and temperature parameters of neutron irradiation to maximum damaging dose of $77 \mathrm{dpa}$ on characteristics of porosity formed in steel $0.07 \mathrm{C}-16 \mathrm{Cr}-19 \mathrm{Ni}-2 \mathrm{Mo}-2 \mathrm{Mn}-\mathrm{Ti}-\mathrm{Si}-\mathrm{V}-\mathrm{P}-\mathrm{B}$. Phys. Met Metallogr. 2014, 115, 625-633. [CrossRef]

7. International Atomic Energy Agency. Structural Materials for Liquid Metal Cooled Fast Reactor Fuel Assemblies-Operational Behavior: IAEA Nuclear Energy Series No. NF-T-4.3; International Atomic Energy Agency: Vienna, Austria, 2012; ISBN 9789201275103.

8. Akkuzin, S.A.; Litovchenko, I.Y. The influence of deformation and short-term high-temperature annealing on the microstructure and mechanical properties of austenitic steel 17Cr-14Ni-3Mo (316 type). Russ. Phys. J. 2019, 62, 1511-1517. [CrossRef] 
9. Yan, F.K.; Liu, G.Z.; Tao, N.R.; Lu, K. Strength and ductility of 316 austenitic stainless steel strengthened by nano-scale twin bundles. Acta Mater. 2012, 60, 1059-1071. [CrossRef]

10. Dehghan-Manshadi, A.; Barnett, M.R.; Hodgson, P.D. Recrystallization in AISI 304 austenitic stainless steel during and after hot deformation. Mater. Sci. Eng. A 2008, 485, 664-672. [CrossRef]

11. Nkhoma, R.K.C.; Siyasiya, C.W.; Stumpf, W.E. Hot workability of AISI 321 and AISI 304 austenitic stainless steels. J. Alloys Compd. 2014, 595, 103-112. [CrossRef]

12. Sun, H.; Sun, Y.; Zhang, R.; Wang, M.; Tang, R.; Zhou, Z. Hot deformation behavior and microstructural evolution of a modified 310 austenitic steel. Mater. Des. 2014, 64, 374-380. [CrossRef]

13. Yanushkevich, Z.; Lugovskaya, A.; Belyakov, A.; Kaibyshev, R. Deformation microstructures and tensile properties of an austenitic stainless steel subjected to multiple warm rolling. Mater. Sci. Eng. A 2016, 667, 279-285. [CrossRef]

14. Ghazani, M.S.; Eghbali, B. Characterization of the hot deformation microstructure of AISI 321 austenitic stainless steel. Mater. Sci. Eng. A 2018, 730, 380-390. [CrossRef]

15. Litovchenko, I.; Akkuzin, S.; Polekhina, N.; Almaeva, K.; Moskvichev, E. Structural transformations and mechanical properties of metastable austenitic steel under high temperature thermomechanical treatment. Metals 2021, 11, 645. [CrossRef]

16. Dolzhenko, P.; Tikhonova, M.; Kaibyshev, R.; Belyakov, A. Peculiarities of DRX in a highly-alloyed austenitic stainless steel. Materials 2021, 14, 4004. [CrossRef]

17. Zhao, D.; Ren, L.; Wang, Y.; Wang, W.; Zhu, Z.; Fu, W. Hot deformation behaviors of as cast 321 austenitic stainless steel. Metals 2021, 11, 1245. [CrossRef]

18. Li, H.; Gao, L.; Song, Y.; Ma, L.; Liu, H.; Li, J.; Zhao, G. Flow stress behavior and microstructure evolution of austenitic stainless steel with low copper content during hot compression deformation. Crystals 2021, 11, 1408. [CrossRef]

19. Akkuzin, S.A.; Litovchenko, I.Y.; Tyumentsev, A.N.; Chernov, V.M. Microstructure and mechanical properties of austenitic steel EK-164 after thermomechanical treatments. Russ. Phys. J. 2019, 62, 698-704. [CrossRef]

20. Wang, S.J.; Jozaghi, T.; Karaman, I.; Arroyave, R.; Chumlyakov, Y.I. Hierarchical evolution and thermal stability of microstructure with deformation twins in 316 stainless steel. Mater. Sci. Eng. A 2017, 694, 121-131. [CrossRef]

21. Torganchuk, V.; Belyakov, A.; Kaibyshev, R. Effect of rolling temperature on microstructure and mechanical properties of $18 \% \mathrm{Mn}$ TWIP/TRIP steels. Mater. Sci. Eng. A 2017, 708, 110-117. [CrossRef]

22. Yanushkevich, Z.; Dobatkin, S.V.; Belyakov, A.; Kaibyshev, R. Hall-Petch relationship for austenitic stainless steels processed by large strain warm rolling. Acta Mater. 2017, 136, 39-48. [CrossRef]

23. Belyakov, A.; Miura, H.; Sakai, T. Dynamic recrystallization under warm deformation of a 304 type austenitic stainless steel. Mater. Sci. Eng. A 1998, 255, 139-147. [CrossRef]

24. Li, C.; Huang, L.; Zhao, M.; Zhang, X.; Li, P. Influence of hot deformation on dynamic recrystallization behavior of 300M steel: Rules and modelling. Mater. Sci. Eng. A 2020, 797, 139925. [CrossRef]

25. Zhao, M.; Huang, L.; Li, C.; Li, P. Evaluation of the deformation behaviors and hot workability of a high-strength low-alloy steel. Mat. Sci. Eng. A 2021, 810, 141031. [CrossRef]

26. Donadille, C.; Valle, R.; Dervin, P.; Penelle, R. Development of texture and microstructure during cold-rolling and annealing of f.c.c. alloys: Example of an austenitic stainless steel. Acta Metall. 1989, 37, 1547-1571. [CrossRef]

27. Huang, A.; Wang, Z.; Liu, X.; Yuan, Q.; Ye, J.; Zhang, Y. Dynamic strain aging and serrated flow behavior of Cr-Ti-B low carbon steel during warm deformation. Mater. Charact. 2021, 172, 110828. [CrossRef]

28. Nikulin, I.; Kaibyshev, R. Deformation behavior and the Portevin-Le Chatelier effect in a modified 18Cr-8Ni stainless steel. Mater. Sci. Eng. A 2011, 528, 1340-1347. [CrossRef]

29. Kim, D.W.; Ryu, W.-S.; Hong, J.H. Effect of nitrogen on the dynamic strain ageing behavior of type 316L stainless steel. J. Mater. Sci. 1998, 33, 675-679. [CrossRef]

30. Rodriguez, P.; Venkadesan, S. Serrated plastic flow revisited. Solid State Phenom. 1995, 42-43, 257-266.

31. Akkuzin, S.A.; Litovchenko, I.Y. Features of mechanical properties of reactor austenite steel under conditions of tensile tests at various temperatures. Appl. J. Tambov Univ. Reports. Ser. Nat. Technol. Sci. 2018, 23, 11-14. (In Russian) [CrossRef] 